Seok, S., \& DaCosta, B. (2017). Grade Point Level, Reading Fluency, and Perceived Digital Reading Ability of Video Game Players and Nonplayers. Journal of Educational Technology Development and Exchange,

10(1), 41-53.

\title{
Grade Point Level, Reading Fluency, and Perceived Digital Reading Ability of Video Game Players and Nonplayers
}

\author{
Soonhwa Seok \\ Korea University \\ Boaventura DaCosta \\ Solers Research Group
}

\begin{abstract}
This study compared grade point level, silent contextual reading fluency, and perceived digital reading ability of 1,206 South Korean video game players and nonplayers in grades 9 through 12. The findings strengthen results reported in the literature while also contributing new information. Nonplayers had better grades, a finding that supports previous research showing that gameplay can negatively influence academic performance. Nonplayers were better readers, a finding in disagreement with studies showing that Internet use, to include video game play, can help with reading performance. While players held higher views of themselves regarding their digital reading ability, these perceptions were not aligned with their grades and reading test scores as well as their online activities when compared to their nonplayer counterparts.
\end{abstract}

Keywords: Grade Point Level, Literacy, Perceived Digital Reading Ability, Silent Contextual Reading Fluency, Video Games

\section{Introduction}

Technology has made a significant contribution to the field of literacy (Chen, Hwang, \& Tsai, 2014; Chu, 2014). For example, advancements in mobile devices have propelled the popularity of e-books, creating new ways to read text along with easy access to content once only available in print. Indeed, it could be argued that technological advancements have played an intricate role in forcing society to rethink how it views literacy (Luce-Kapler, 2007; Mills \& Levido, 2011; Pilgrim, Bledsoe, \& Reily, 2012), with students' skills, knowledge, and use of digital technology constituting what may be called "digital literacy" (Burgess, Price, \& Caverly, 2012).

Digital literacy can be broadly viewed as the ability to understand and use information presented in multiple formats from different sources (Glister, 1997). To search for, create, reproduce, manipulate, 
use, and evaluate information for a variety of purposes, including reading and interpreting media (Jones-Kavalier \& Flannigan, 2006). Digital literacy is consequently infused into everyday life (Burnett, 2014), influencing how students complete school assignments, acquire information, are entertained, and participate in society (Mills, 2010; Seok, DaCosta, \& Yu, 2015).

Even though new forms of literacy based on technological advancements may generally be viewed as promising, this viewpoint has become a matter of debate. For example, reports showing that standardized reading test scores of U.S. high school students are declining or remaining unchanged (e.g., The Nation's Report Card, 2015) have led to speculation that the Internet, at least in part, has contributed to this overall drop in reading (Bradshaw \& Nichols, 2004). Similar conclusions have been offered with regard to other electronic media, such as video games, arguing that a decline in reading correlates with increased use in certain technologies (Bradshaw \& Nichols, 2004).

These contrasting viewpoints should come as no surprise. The educational potential of video games has long been the subject of fierce debate (Guillén-Nieto \& Aleson-Carbonell, 2012). Thus, opponents have branded these games as mind-numbing activities that divert young people's attention from their studies (Kirriemuir \& McFarlane, 2004), claiming that time spent playing would be time better spent in the pursuit of better grades (Yurov, Yurova, Kwak, \& Ku, 2014). Conversely, advocates have proposed that video games are a powerful learning medium (Kirriemuir \& McFarlane, 2004).

Due to these conflicting claims, the effectiveness of playing video games in the context of basic reading development as well as literacy learning development is an area that needs further study (Commeyras, 2009); in particular, the academic impact of video games is inconclusive (Barlett, Anderson, \& Swing, 2009).

\subsection{Purpose of the Research}

Given the increasing importance of digital literacy and the continued deliberation about the academic possibilities of video games, this research aimed to determine if video game play contributes to lower reading scores. To address this aim, reading performance was explored in the context of video game play by comparing grade point level, reading fluency, and perceived digital reading ability of players and nonplayers, resulting in the following research questions:

Research Question 1: Are there differences in grade point level between video game players and nonplayers?

Research Question 2: Are there differences in silent contextual reading fluency between video game players and nonplayers?

Research Question 3: Are there differences in perceived digital reading ability between video game players and nonplayers? If so, what are they?

Gameplay and online activities were also examined to help frame the findings.

This study does not debate the pros and cons of using video games in the classroom. Rather it contributes preliminary empirical data to the ongoing discussion of video games as a literacy tool. Educators, practitioners, researchers, and stakeholders may find this investigation and findings useful as they integrate digital technology into reading curricula. 


\section{Video Games and Literacy}

There is widespread concern that students who play video games excessively are less willing to spend the time needed on academic study (Cummings \& Vandewater, 2007). Thus, play can displace schoolwork, resulting in lower academic reading performance (e.g., Cummings \& Vandewater, 2007; Suziedelyte, 2015; Weis \& Cerankosky, 2010). There is research to support this fear. Examining a nationally representative sample of 1,491 U.S. children, 10 to 19 years old, Cummings and Vandewater (2007) found that those who played video games spent $30 \%$ less time reading and $34 \%$ less time doing homework than nonplayers. Similarly, Weis and Cerankosky (2010) noted that the U.S. males in their study who had received game consoles spent more time playing and less time on academics, resulting in lower reading and writing scores compared to those without consoles.

Largely, research conducted in the United States and abroad has pointed to the addictive nature of video games and the effect on achievement (Barlett et al., 2009), with evidence showing that gaming can negatively impact academics. For example, Anderson and Dill (2000) looked at the effects of violent games among 227 U.S. undergraduate students, reporting that longterm play was significantly and negatively correlated to grade point average (GPA). In a later study, Borgonovi (2016) found that excessive play was associated with reduced academic achievement based on an analysis of 2012 Programme for International Student Assessment (PISA) data on 145,953 students from 26 countries. Similarly, Choo et al.'s (2010) examination of play among 2,998 children and adolescents from six primary and six secondary schools in Singapore revealed that pathological play helped predict poor academic performance, after controlling for time. Yeh (2016) investigated computer gaming among 355 Taiwanese children across 20 elementary schools, concluding greater play correlated significantly with lower school achievement. Finally, in a sample of 236 Malaysian secondary school students, Eow, Wan Ali, Mahmud, and Baki (2009) found a significant difference in academic achievement scores, with nonplayers outperforming players.

However, not all video game research is discouraging. Although Borgonovi (2016) found that excessive gaming may hinder academic performance, she also concluded that moderate use of single-player games may promote positive student outcomes. Further, some research refutes claims that video games are academically harmful (Steinkuehler, 2010). For example, Drummond and Sauer (2014) reanalyzed 2009 PISA data on more than 192,000 students across 22 countries. Contrary to claims that gaming can impair academic performance, these authors found that differences regarding academics were negligible for science, mathematics, and reading. Rasmusson and Åberg-Bengtsson (2015) examined Swedish PISA data, concluding males better performed in digital reading because of computer game play.

Video games may be especially helpful for improving reading skills among adolescents with and without disabilities. For example, Franceschini et al. (2013) found that, when compared to more than a year of spontaneous reading development and more than or equal to highly demanding traditional reading treatments, 12 hours of action-based gameplay improved adolescents' reading speed without diminishing accuracy. Attentional skills were also found to improve during gameplay, indirectly translating into better reading ability. Action-based games are particularly interesting because they may improve attentional abilities (Green \& Bavelier, 2003, 
2012; Green, Pouget, \& Bavelier, 2010). For example, Lieury, Lorant, Trosseille, Champault, and Vourc'h (2014) described the work of Green and Bavelier (2003, 2006, 2007), who found that players of actionbased games benefited in terms of improved performance in selective attention and visual discrimination. Similarly, Strobach, Frensch, and Schubert (2012) discovered gamers were more efficient in dual-task situations, processed simultaneously or sequentially (but not for single-task situations); West, Stevens, Pun, and Pratt (2008) and Boot, Kramer, Simons, Fabiani, and Gratton (2008) reported better visual perception and greater anticipation of events among players; and finally, Jaeggi, Buschkuehl, Jonides, and Shah (2011) showed a positive effect on information processing speed.

These findings help paint a significantly different picture of video games and literacy (Black \& Steinkuehler, 2007), showing these games do not hinder, but may indeed promote different types of literacy, from information seeking to content production (Squire \& Steinkuehler, 2005). Therefore, reading should be viewed an important part of the gaming culture (Steinkuehler, 2011), stimulating reading in certain types of materials (Rich, 2008), such as game-related content (Lenhart et al., 2008; Niemeyer \& Gerber, 2015). For example, Squire and Steinkuehler (2005) found that video games can fuel interest in different topics related to history, politics, economics, and geography, pointing to the fact that nearly every student they worked with who played Age of Empires, Civilization, or Rome: Total War checked out a book on related topics. Consequently, video games should not be viewed as a reading replacement, but rather a way to enhance reading (Steinkuehler, 2011; Steinkuehler, Compton-Lilly, \& King, 2010), possibly revealing insights into helping children read (Compton-Lilly, 2007).

\section{Method}

The study took place at seven college preparatory high schools near Seoul, South Korea. This country was chosen because of its forward thinking towards technological advancement and promotion. The schools were selected because they emphasized English in their curriculum. Altogether, South Korea offered an appropriate setting from which to draw technically adept and English-speaking participants.

\subsection{Participants}

A total of 1,206 students in grades 9 through 12 voluntarily participated in the study. As shown in Table 1, the participants were predominantly 18 years of age or older $(67 \%, n=807)$ and male $(68 \%, n=821)$.

Table 1. Participant Demographics

\begin{tabular}{|l|l|c|}
\hline \multicolumn{1}{|c|}{ Items } & & Freq. $(\%)$ \\
\hline \multirow{4}{*}{ Age } & 15 or younger & $2(.2 \%)$ \\
\cline { 2 - 3 } & 16 & $23(1.9 \%)$ \\
\cline { 2 - 3 } & 17 & $374(31.0 \%)$ \\
\cline { 2 - 3 } & 18 or older & $807(66.9 \%)$ \\
\hline \multirow{4}{*}{ Gender } & Male & $821(68.1 \%)$ \\
\cline { 2 - 3 } & Female & $385(31.9 \%)$ \\
\hline \multirow{3}{*}{ Grade Level } & 9 th & $6(0.5 \%)$ \\
\cline { 2 - 3 } & 10 th & $172(14.3 \%)$ \\
\cline { 2 - 3 } & 11 th & $899(74.5 \%)$ \\
\cline { 2 - 3 } & 12 th & $129(10.7 \%)$ \\
\hline
\end{tabular}




\subsection{Materials}

Instruments comprised the Test of Silent Contextual Reading Fluency (2nd ed.; Hammill, Wiederholt, \& Allen, 2006) and a survey designed to examine preferences for digital material. Demographic information was also collected.

\subsubsection{Test of Silent Contextual Reading} Fluency (TOSCRF). The TOSCRF assesses general silent reading ability of elementaryto secondary-level students (Hammill et al., 2006) by measuring the rate at which students can identify distinct words found in increasingly difficult texts based on meaning and syntax. Readers are given 10 minutes to draw lines between as many words as they can, with scoring based on word count in lines as well as the summation of all words.

3.2.2. Survey. The survey sought to examine students' reading preferences for digital material. Items were derived from a research synthesis concentrating on reading in a number of contexts to include video games.

\subsection{Procedure}

The principal investigator (PI) met with the principals, vice principals, and a research teacher from each participating school to discuss the investigation, establish protocols, and obtain permissions. The paper-and-pencil TOSCRF and survey were administered to the students in their classrooms by the PI with assistance from a homeroom teacher and an English teacher from each school. The TOSCRF is only available in English, requiring the participation of English teachers; this was also the reason why emphasis was placed on schools that taught English as part of their curriculum.

\subsection{Ethical Clearance and Informed Consent}

Letters about ethical clearance and informed consent were sent to the schools to obtain the necessary permissions. Informed consent letters were also sent to parents of students 17 and younger.

\section{Results and Discussion}

The participants self-reported their game play by responding to a series of items on the survey that asked whether or not they played video games, how often and what types of games they played, and what devices they used. Those who responded that they played and answered the other gaming-related items were grouped as video game players $(49 \%, n$ $=589$ ), whereas those reported that they never played and did not answer the other items were grouped as nonplayers $(51 \%, n=617)$.

Gameplay was mostly a weekly occurrence $(50.4 \%, n=297)$, followed by daily $(25.8 \%, n=152)$, and monthly $(23.8 \%$, $n=140)$; lasted $1-4 \mathrm{hrs}(39.2 \%, n=231), 4-8$ hrs $(14.1 \%, n=83)$, and $8-12$ hrs $(11.4 \%$, $n=67)$; primarily comprised the genres of strategy $(22.1 \%, n=130)$, sports $(20.4 \%, n=$ $120)$, action $(15.4 \%, n=91)$, and role-playing $(13.4 \%, n=79)$; and largely took place on personal computers $(67.2 \%, n=396)$, mobile phones $(26.7 \%, n=157)$, and consoles or dedicated handhelds $(5.3 \%, n=31)$. Players were predominantly male $(86.6 \%, n=510$; female, $13.4 \%, n=79$ ), with gender evenly distributed among nonplayers (male, 50.4\%, $n=311$; female, $49.6 \%, n=306$ ). Similar findings have been reported in South Korean studies examining video game play (e.g., DaCosta \& Seok, 2017a; Seok \& DaCosta, 2016), suggesting that the groups in the present study were representative.

The participants also self-reported their online activities by responding to 
an item asking the primary reason for going online. A chi-squared test revealed significant differences between the groups, $\chi^{2}(8)=314.26, p=.00, \mathrm{CI}=95 \%$, with the nonplayers expressing the most interest in the common and everyday activities shown in Table 2. The exception was playing games. While reported by a third $(n=198)$ of the players, interestingly, $16 \%(n=97)$ of the nonplayers also reported the activity. Further analysis revealed these participants were overwhelmingly female $(96.9 \%, n=94)$ mobile phone owners $(83 \%, n=78)$. Perhaps suggesting the participants were mobile game players, not viewing themselves as video game players, but rather seeing their game play as a casual or social activity (DaCosta \& Seok, 2017b).

\subsection{Academic Performance}

Independent-samples t-tests were conducted to compare grade point level and TOSCRF scores between the groups. Significant differences were found for grade point level, $t(1204)=-3.71, p=.00$, between players $(M=3.55, S D=1.78)$ and nonplayers $(M=3.18, S D=1.72)$ as well as TOSCRF scores, $t(1204)=5.69, p=.00$, between players $(M=68.20, S D=57.96)$ and nonplayers $(M=92.28, S D=85.68)$.

4.1.1. Grade Point Level. The grading scale for high school in South Korea is divided into nine rankings, representing students' relative standing among all other students in a class, with 1 representing the best-performing students and 9, the worst. In terms of Research Question 1, differences were found in grade point level between the two groups. While the

Table 2. Main Online Activities of Players and Nonplayers

\begin{tabular}{|l|c|c|}
\hline \multirow{2}{*}{ Read } & \multicolumn{2}{|c|}{ Freq. (\%) } \\
\cline { 2 - 3 } & Player & Nonplayer \\
\hline Write & $68(11.5 \%)$ & $75(12.2 \%)$ \\
\hline Make calls (e.g., VoIP) & $13(2.2 \%)$ & $16(2.6 \%)$ \\
\hline $\begin{array}{l}\text { Stream content (e.g., movies, television, } \\
\text { videos) }\end{array}$ & $6(1 \%)$ & $15(2.4 \%)$ \\
\hline Play games & $83(14.1 \%)$ & $96(15.6 \%)$ \\
\hline Surf (for entertainment) & $198(33.6 \%)$ & $97(15.7 \%)$ \\
\hline Social media & $146(24.8 \%)$ & $177(28.7 \%)$ \\
\hline Upload movies/video & $14(2.4 \%)$ & $23(3.7 \%)$ \\
\hline Schoolwork & $1(0.2 \%)$ & $2(0.3 \%)$ \\
\hline Email & $23(3.9 \%)$ & $47(7.6 \%)$ \\
\hline Stream music & - & $3(0.5 \%)$ \\
\hline Other & $17(2.9 \%)$ & $38(6.2 \%)$ \\
\hline
\end{tabular}


rankings among the players followed a normal distribution, the grade points were skewed among nonplayers favoring better grades, as depicted in Figure 1. Although some studies have found no conclusive evidence to support the idea that video game play has any bearing on school performance, or at best a negligible influence, the current finding supports research conducted in the U.S. and in Asian countries (e.g., Eow et al., 2009) suggesting that gameplay can negatively impact academic achievement. in the identification of 80 and more words and players outpacing nonplayers in the identification of 79 words and fewer. Thus, in terms of Research Question 2, differences were found between the two groups in silent contextual reading fluency. Overall, nonplayers were the better readers - a finding that is at odds with research showing that Internet use, to include video game play, has little to do with poor reading performance (e.g., Franceschini et al., 2013; Rasmusson \& Åberg-Bengtsson, 2015).

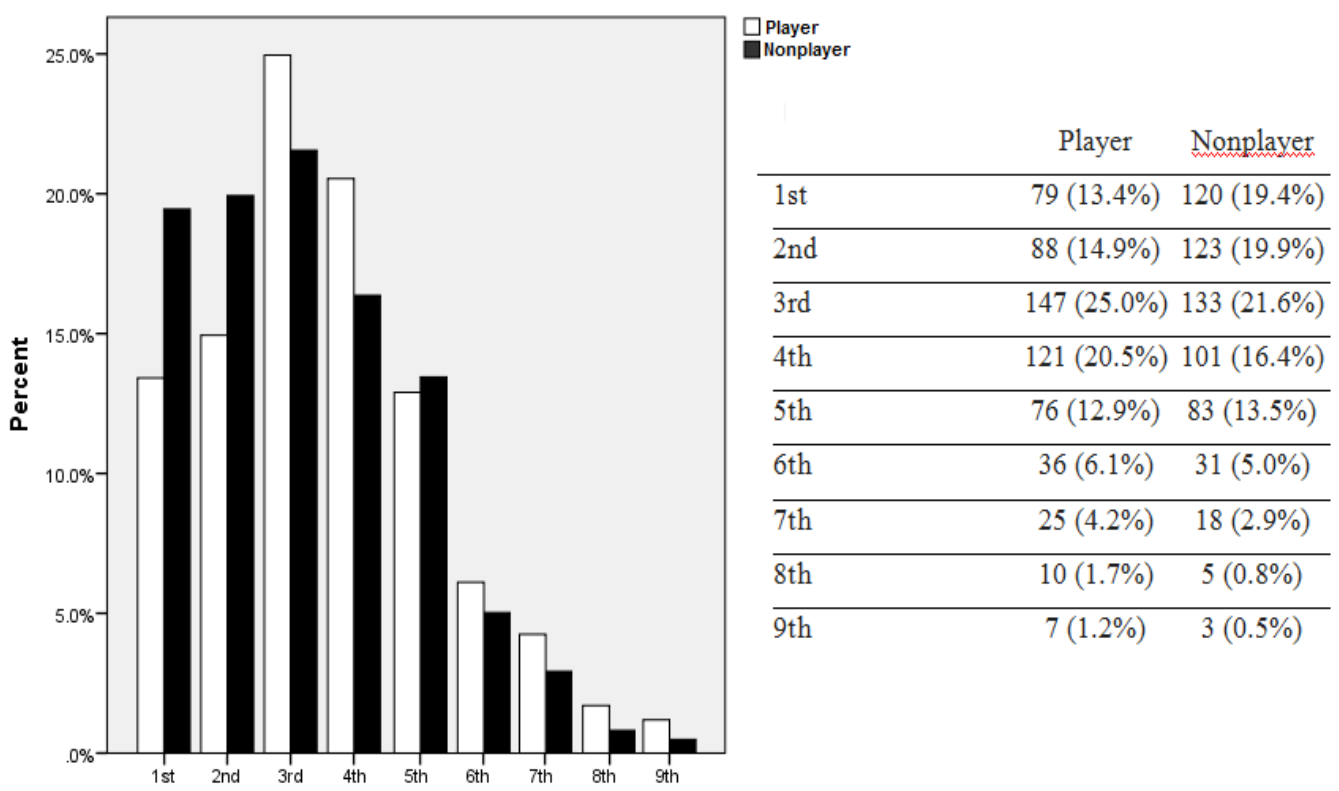

Figure 1. Comparison of grade point level between players and nonplayers.

4.1.2. TOSCRF Scores. The same results were found, in part, for silent reading ability. Although Figure 2 depicts similar distributions between the groups, aggregated TOSCRF scores showed that nonplayers $(42 \%, n=$ 257) outperformed players $(25 \%, n=147)$

\subsection{Perceived Digital Reading Ability}

An independent-samples $t$ test revealed significant differences in favor of players when comparing the mean scores of perceived digital reading ability between the two groups. 

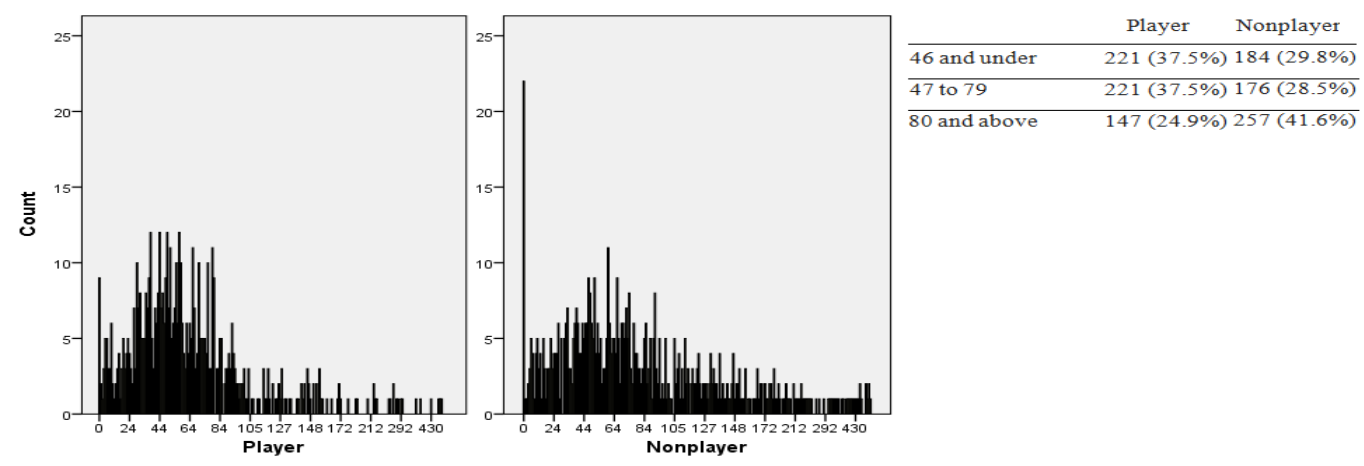

Figure 2. Comparison of TOSCRF scores between players and nonplayers.

Thus, in response to Research Question 3, differences were found in perceived digital reading ability between the two groups. As shown in Table 3, the means of the players were higher regarding their ability to: (a) discuss what has been read (players, $M=3.7$, $S D=.84$; nonplayers, $M=3.57, S D=.79)$; (b) ask appropriate questions about the reading (players, $M=3.76, S D=.84$; nonplayers, $M=3.65, S D=.78$ ); (c) understand charts and graphs (players, $M=3.68, S D=.84$; nonplayers, $M=3.57, S D=.77)$; (d) associate prior knowledge to text (players, $M=3.86$, $S D=.81$; nonplayers, $M=3.73, S D=.76$ ); (e) acquire main ideas from reading (players, $M$ =3.82, $S D=.84$; nonplayers, $M=3.71, S D=$ .77 ); and (f) skim for information (players, $M$ =3.71, $S D=.84$; nonplayers, $M=3.61, S D=$ $.83)$.

As discussed earlier, some research has proposed that video games can help improve performance in several areas of cognitive processing, revealing that gamers (a) perform better in select attention and visual discrimination (e.g., Green \& Bavelier, 2003, 2006, 2007); (b) are more efficient in dualtask situations (e.g., Strobach et al., 2012); and (c) process information at a higher speed (e.g., Jaeggi et al., 2011). These findings may explain the cognitive abilities representing the items in Table 3.

However, the nonplayers in the current study outperformed the players both in grade point level and reading scores, as measured by standardized testing (TOSCRF), suggesting the players held perceptions about their abilities that were not aligned with their test scores. This finding is further exacerbated by their online use. Nonplayers had higher means across the academic and leisure activities shown in Table 2. Nonplayers showed more interest in completing schoolwork online $(8 \%, n=47$; players, $4 \%, n=23)$ and greater attention to reading $(12 \%, n=75$; players, $11.5 \%, n=68)$ and writing $(3 \%, n=16$; players, $2 \%, n=13)$. Altogether, this may be a new finding worthy of future study.

\subsection{Limitations and Future Research}

As with any research, this study is not without its limitations. First, there are validity challenges associated with self-reported data. While it is believed that the participants responded truthfully, the potential for bias remains. For example, although the nonplayers reported that they never played video games in a battery of items, a small percentage reported 
Table 3. Significant Variables in Perceived Digital Reading Ability of Players and Nonplayers

\begin{tabular}{|l|l|l|l|l|l|c|}
\hline Items & \multicolumn{2}{|c|}{ Players } & \multicolumn{2}{c|}{ Nonplayers } & & \\
\hline & $M$ & $S D$ & $M$ & $S D$ & $t$ & $P$ \\
\hline Easily discuss what has been read & 3.7 & .84 & 3.57 & .79 & -2.896 & $.004^{* *}$ \\
\hline $\begin{array}{l}\text { Ask appropriate questions about what } \\
\text { is read }\end{array}$ & 3.76 & .84 & 3.65 & .78 & -2.201 & $.028^{*}$ \\
\hline Understand charts and graphs & 3.68 & .84 & 3.57 & .77 & -2.337 & $.020^{*}$ \\
\hline Associate prior knowledge to text & 3.86 & .81 & 3.73 & .76 & -2.937 & $.003^{* *}$ \\
\hline Get the main ideas in reading & 3.82 & .84 & 3.71 & .77 & -2.560 & $.011^{*}$ \\
\hline $\begin{array}{l}\text { Skim for information (nonlinear) } \\
\text { when reading }\end{array}$ & 3.71 & .84 & 3.61 & .83 & -1.979 & $.048^{*}$ \\
\hline
\end{tabular}

$* * \mathrm{p}<0.01, * \mathrm{p}<0.05$.

gameplay as their most common online activity. Suggesting this percentage may not have viewed their behavior as video game play. Also, overwhelmingly female mobile phone owners, the finding may warrant further study into the role of gender and mobile gaming in the context of literacy. There are also concerns regarding grades because of the participating schools' emphasis on English, calling into question the generalizability of the findings. Further study is warranted using other populations, to include students from non-college preparatory schools as well as students from other parts of the world because the students may have exhibited perceptions and preferences aligned with South Korea's forward-thinking attitude towards technology. Finally, direct comparisons to existing research are difficult given the paucity of empirical studies on video games and silent reading ability.

\section{Conclusion}

To help further understand the impact of video games on literacy, this study answered three research questions comparing grade point level, silent contextual reading fluency, and perceived digital reading ability of South Korean video game players and nonplayers. Findings strengthen results reported in the literature while also possibly contributing new information. Specifically, nonplayers had better grades, a finding supporting research showing that gameplay can negatively influence academic performance. Further, nonplayers were better readers, a finding in disagreement with studies showing that Internet use, to include video game play, can help readers. In addition, while players held higher views of themselves regarding their digital reading ability, their perceptions were not aligned with their grades and reading test scores as well as their online academic and leisure activities when compared to their nonplayer counterparts.

All in all, the current investigation does not provide evidence of the literacy potential of video games; rather, it suggests that these games play some role in decreased academic reading performance. However, as discussed, there are possible explanations for these results, warranting caution and the need for more sophisticated empirical investigations in the future. 


\section{References}

Anderson, C. A., \& Dill, K. E. (2000). Video games and aggressive thought, feelings, and behavior in the laboratory and in life. Journal of Personality and Social Psychology, 78(4), 772-290. doi:10.1037// O022-3514.78.4.772

Barlett, C. P., Anderson, C. A., \& Swing, E. L. (2009). Video game effects - Confirmed, suspected, and speculative. A review of the evidence. Simulation Gaming, 40(3), 377-403. doi:10.1177/1046878108327539

Black, R. W., \& Steinkuehler, C. (2009). Literacy in virtual worlds. In L. Christenbury, R. Bomer, \& P. Smagorinsky (Eds.), Handbook of adolescent literacy research (pp. 271-286). New York, NY: Guilford Press.

Boot, W. R., Kramer, A. F., Simons, D. J., Fabiani, M., \& Gratton, G. (2008). The effects of video game playing on attention, memory, and executive control. Acta Psychologica, 129(3), 387-398. doi:10.1016/j.actpsy.2008.09.005

Borgonovi, F. (2016). Video gaming and gender differences in digital and printed reading performance among 15 -yearolds students in 26 countries. Journal of Adolescents, 48, 45-61. doi:10.1016/ j.adolescence.2016.01.004

Bradshaw, T., \& Nichols, B. (2004). Reading at risk: A survey of literary reading in America (Research Division Report No. 46). Washington, DC: National Endowment for the Arts.

Burgess, M. L., Price, D. P., \& Caverly, D. C. (2012). Digital literacies in multiuser virtual environments among college-level developmental readers. Journal of College Reading and Learning, 43(1), 13-30.

Burnett, C. (2014). Investigating pupils' interactions around digital texts: A spatial perspective on the "classroom-ness" of digital literacy practices in schools. Educational Review, 66(2), 192-209. doi: 10.1080/00131911.2013.768959

Chen, C.-H., Hwang, G.-J., \& Tsai, C.-H. (2014). A progressive prompting approach to conducting context-aware learning activities for natural science courses. Interacting With Computers, 26(4), 348359. doi:10.1093/iwc/iwu004

Choo, H., Gentile, D. A., Sim, T., Li, D., Khoo, A. \& Liau, A. K. (2010). Pathological video-gaming among Singaporean youth. Annals Academy of Medicine, 39(11), 822-829.

Chu, H.-C. (2014). Potential negative effects of mobile learning on students' learning achievement and cognitive load - A format assessment perspective. Journal of Educational Technology \& Society, 17(1), 332-344.

Commeyras, M. (2009). Drax's reading in Neverwinter Nights: With a tutor as henchman. E-Learning and Digital Media, 6(1), 43-53. doi:10.2304/elea.2009.6.1.43

Compton-Lilly, C. (2007). What can video games teach us about teaching reading? The Reading Teacher, 60(8), 718-727. doi:10.1598/RT.60.8.2

Cummings, H. M., \& Vandewater, E. A. (2007). Relation of adolescent video game play to time spent in other activities. Archives of Pediatrics and Adolescent Medicine, 161(7), 684-689. doi:10.1001/ archpedi.161.7.684

DaCosta, B., \& Seok, S. (2017a). Factors that explain adolescent and young adult mobile game play, part 1: A quantitative examination of the characteristics describing the casual player. In R. Zheng \& M. Gardner (Eds.), Handbook of research on serious games for educational applications (pp. 320-339). Hershey, PA: IGI Global. doi:10.4018/978-1-52250513-6.ch015

DaCosta, B., \& Seok, S. (2017b). Factors 
that explain adolescent and young adult mobile game play, part 2: A quantitative examination of the casual player in the context of age and gender. In R. Zheng \& M. Gardner (Eds.), Handbook of research on serious games for educational applications (pp. 340-365). Hershey, PA: IGI Global. doi: 10.4018/978-1-52250513-6.ch016.

Drummond, A., \& Sauer, J. D. (2014). Video-games do not negatively impact adolescent academic performance in science, mathematics or reading. PLoS ONE, 9(4), e87943. doi:10.1371/journal. pone. 0087943

Eow, Y. L., Wan Ali, W. Z. B., Mahmud, R. B., \& Baki, R. (2009). Form one students' engagement with computer games and its effect on their academic achievement in a Malaysian secondary school. Computers \& Education, 53(4), 1082-1091. doi:10.1016/j.compedu.2009.05.013

Franceschini, S., Gori, S., Ruffino, M., Viola, S., Molteni, M., \& Facoetti, A. (2013). Action video games make dyslexic children read better. Current Biology, 23(6), 462-466. doi:10.1016/ j.cub.2013.01.044

Glister, P. (1997). Digital literacy. New York, NY: Wiley and Computer Publishing.

Green, C. S., \& Bavelier, D. (2003). Action video game modifies visual selective attention. Nature, 423(6939), 534-537. doi:10.1038/nature01647

Green, C. S., \& Bavelier, D. (2006). Effect of action video games on the spatial distribution of visuospatial attention. Journal of Experimental Psychology, 32(6), 1465-1478. doi:10.1037/00961523.32.6.1465

Green, C. S., \& Bavelier, D. (2007). Actionvideo-game experience alters the spatial resolution of vision. Psychological Science, 18(1), 88-94. doi:10.1111/j.14679280.2007.01853.x
Green, C. S., \& Bavelier, D. (2012). Learning, attentional control, and action video games. Current Biology, 22(6), R197R206. doi:10.1016/j.cub.2012.02.012

Green, C. S., Pouget, A., \& Bavelier, D. (2010). Improved probabilistic inference as a general learning mechanism with action video games. Current Biology, 20(17), 1573-1579. doi:10.1016/ j.cub.2010.07.040

Guillén-Nieto, V., \& Aleson-Carbonell, M. (2012). Serious games and learning effectiveness: The case of It's a Deal! Computers and Education, 58(1), 435448. doi:10.1016/j.compedu.2011.07.015

Hammill, D. D., Wiederholt, J. S., \& Allen, E. (2006). Test of Silent Contextual Reading Fluency (TOSCRF). Austin, TX: Pro-Ed.

Jaeggi, S. M., Buschkuehl, M., Jonides, J., \& Shah, P. (2011). Short- and long-term effects of cognitive training. Psychological and Cognitive Sciences, 108(25), 1008110086. doi:10.1073/pnas. 1103228108

Jones-Kavalier, B. R., \& Flannigan, S. L. (2006). Connecting the digital dots: Literacy of the 21 st century. Retrieved from http://er.educause.edu/ articles/2006/1/connecting-the-digitaldots-literacy-of-the-21st-century

Kirriemuir, J., \& McFarlane, A. (2004). Report 8: Literature review in gaming and learning. Future Lab. Retrieved from http://telearn.archives-ouvertes. fr/docs/00/19/04/53/PDF/kirriemuir-j2004-r8.pdf

Lenhart, A., Kahne, J., Middaugh, E., Rankin Macgill, A., Evans, C., \& Vitak, J. (2008). Teens, video games, and civics. Washington, DC: Pew Internet and American Life Project.

Lieury, A., Lorant, S., Trosseille, B., Champault, F., \& Vourc'h, R. (2014). Video games vs. reading and school/ cognitive performances: A study on 27000 middle school teenagers. Educational 
Psychology: An International Journal of Experimental Educational Psychology, Retrieved from http://www.tandfonline. com/doi/abs/10.1080/01443410.2014.923 556 ? journalCode $=$ cedp 20

Luce-Kapler, R. (2007). Radical change and wikis: Teaching new literacies. Journal of Adolescent \& Adult Literacy, 51(3), 214-223. doi:10.1598/JAAL.51.3.2

Mills, K. A. (2010). A review of the "digital turn" in the new literacy studies. Review of Educational Research, 80(2), 246-271. doi:10.3102/0034654310364401

Mills, K. A., \& Levido, A. (2011). iPed: Pedagogy for digital text production. The Reading Teacher, 65(1), 80-91. doi:0.1598/RT.65.1.11

The Nation's Report Card. (2015). Mathematics and reading at grade 12. Retrieved from http://www. nationsreportcard.gov/reading_math_ g12_2015/\#reading

Niemeyer, D. J., \& Gerber, H. R. (2015). Maker culture and "Minecraft": Implications for the future of learning. Educational Media International, 52(3), 216-226. doi:10.1080/09523987.2015.10 75103

Pilgrim, J., Bledsoe, C., \& Reily, S. (2012). New technologies in the classroom. Delta Kappa Gamma Bulletin, 78(4), 16-22.

Rasmusson, M., \& Åberg-Bengtsson, L. (2015). Does performance in digital reading relate to computer game playing? A study of factor structure and gender patterns in 15-year-olds' reading literacy performance. Scandinavian Journal of Educational Research, 59(6), 691-709. doi :10.1080/00313831.2014.965795

Rich, M. (2008, October). The future of reading: Using video games as bait to hook readers. New York Times. Retrieved from http://www.mymontessorihouse. com/2008/10/future-of-reading-usingvideo-games-as.html
Seok, S., DaCosta, B., \& Yu, B. M. (2015). Spelling practice intervention: A comparison of tablet $\mathrm{PC}$ and picture cards as spelling practice methods for students with developmental disabilities. Education and Training in Autism and Developmental Disabilities, 50(1), 84-94.

Seok, S., \& DaCosta, B. (2016). A comparison of the online learning activities and learning style preferences of young adult video game players and nonplayers. Asian Social Science, 12(3), 1-13. doi:10.5539/ ass.v12n $3 \mathrm{p} 1$

Squire, K., \& Steinkuehler, C. (2005, April). Meet the gamer. Library Journal. Retrieved from http://lj.libraryjournal. com/2005/04/gaming/meet-the-gamers/\#

Steinkuehler, C. (2010). Video games and digital literacies. Journal of Adolescent \& Adult Literacy, 54(1), 61-63. doi:10.1598/ JAAL.54.1.7

Steinkuehler, C. (2011). The mismeasure of boys: Reading and online video games (WCER Working Paper No. 2011-3). Madison, WI: University of WisconsinMadison.

Steinkuehler, C., Compton-Lilly, C., \& King, E. (2010). Reading in the context of online games. In K. Gomez, L. Lyons, \& J. Radinsky (Eds.), Proceedings of the 9th International Conference of the Learning Sciences (pp. 222-229). Chicago, IL: International Society of the Learning Sciences.

Strobach, T., Frensch, P. A., \& Schubert, T. (2012). Video game practice optimizes executive control skills in dual-task and task switching situations. Acta Psychologica, 140(1), 13-24. doi:10.1016/ j.actpsy.2012.02.001

Suziedelyte, A. (2015). Media and human capital development: Can video game playing make you smarter? Economic Inquiry, 53(2), 1140-1155. doi:0.1111/ ecin. 12197 
Weis, R., \& Cerankosky, B. C. (2010). Effects of video-game ownership on young boys' academic and behavioral functioning: A randomized, controlled study. Psychological Science, 21(4), 463-470. doi: $10.1177 / 0956797610362670$

West, G. L., Stevens, S. A., Pun, C., \& Pratt, J. (2008). Visuospatial experience modulates attentional capture: evidence from action video game players. Journal of Vision, 8(16), 1-9. doi:10.1167/8.16.13

Yeh, D-Y. (2016). Relationships among Taiwanese children's computer game use, academic achievement and parental governing approach. Research in Education, 95(1), 44-60. doi:10.7227/ RIE.0025

Yurov, K. M., Yurova, Y. V., Kwak, M., \& Ku, C-H. (2014). The effect of psychological and environmental factors on academic performance of video gamers. Issues in Information System, 15(2), 393-398.

\section{Contact the Author}

\section{Dr. Soonhwa Seok}

Research Professor

Korea University

Email: sunaseok@yahoo.com

\section{Dr. Boaventura DaCosta}

Research Associate

Solers Research Group

Email: bdacosta@solersresearchgroup.com 